\title{
Neural Signature for Auditory Hallucinations in Schizophrenia: A High-Resolution Positron Emission Tomography Study with Fludeoxyglucose $\left({ }^{18} \mathrm{~F}\right)$
}

\author{
Jong-Hoon Kim ${ }^{1,2}$, Young Don Son ${ }^{3}$, Jeong-Hee Kim ${ }^{4}$, Hyo-Jong Lee ${ }^{5}$, Nam-ln Kang ${ }^{6}$, Gyung Ho Chung ${ }^{7,8}$, \\ Jong-Il Park ${ }^{7,9}$, Yin Cui ${ }^{7,9}$, Woo-Sung Kim ${ }^{7,9}$, Young-Chul Chung ${ }^{7,9}$ \\ ${ }^{1}$ Department of Psychiatry, Gachon University Gil Medical Center, Gachon University School of Medicine, ${ }^{2}$ Neuroscience Research Institute, \\ ${ }^{3}$ Department of Biomedical Engineering, Gachon University, Incheon, ${ }^{4}$ Research Institute for Advanced Industrial Technology, Korea University, \\ Sejong, ${ }^{5}$ Department of Computer Science and Engineering \& Center for Advanced Image and Information Technology, Chonbuk National \\ University, Jeonju, ${ }^{6}$ Department of Psychiatry, Maeumsarang Hospital, Wanju, ${ }^{7}$ Research Institute of Clinical Medicine of Chonbuk National \\ University-Biomedical Research Institute of Chonbuk National University Hospital, Jeonju, Departments of ${ }^{8}$ Radiology and ${ }^{9}$ Psychiatry, Chonbuk \\ National University Medical School, Jeonju, Korea
}

Objective: Auditory hallucinations $(\mathrm{AHs})$ are a core symptom of schizophrenia. We investigated the neural signature of $\mathrm{AHs}$ by comparing hallucinating patients with schizophrenia with non-hallucinating patients with schizophrenia. Methods: We recruited hallucinating patients with schizophrenia meeting the criteria for persistent, prominent, and predominant AHs $(n=10)$ and non-hallucinating patients with schizophrenia $(n=12)$. Various clinical assessments were performed incluing Psychotic Symptom Rating Scale for Auditory Hallucinations. Using fludeoxyglucose $\left({ }^{18} \mathrm{~F}\right)$ positron emission tomography, regional differences in neural activity between the groups were analyzed.

Results: The regions of interest analysis showed significantly lower standardized uptake value ratio (SUVR) in the superior, middle, and inferior frontal gyri, and higher SUVR in the putamen in patients with AHs versus patients without AHs. These findings were confirmed in the voxel-wise analysis.

Conclusion: Our findings indicate that hypoactivity in the frontal and cingulate gyri, coupled with hyperactivity in the temporal gyrus and putamen, may contribute to the pathophysiology of AHs.

KEY WORDS: Auditory hallucinations; Schizophrenia; Positron-emission tomography; Bottom-up; Top-down.

\section{INTRODUCTION}

Auditory hallucinations (AHs) occur in the general population at a median estimated rate of $4 \%$ to $5 \%{ }^{1)}$ In patients with schizophrenia, the prevalence is quite common, up to $74 \% .^{2)}$ Moreover, $25 \%$ to $50 \%$ of subjects continue to experience them despite medication. ${ }^{3,4)}$ The experience of voices can impact on quality of life, self-esteem, anxiety, depression, suicide attempts, and cognitive

Received: January 26, 2018 / Revised: April 6, 2018 Accepted: April 23, 2018

Address for correspondence: Young-Chul Chung, MD, PhD Department of Psychiatry, Chonbuk National University Medical School, 20 Geonji-ro, Deokjin-gu, Jeonju 54907, Korea

Tel: +82-63-250-2185, Fax: +82-63-275-3157

E-mail: chungyc@jbnu.ac.kr

ORCID: https://orcid.org/0000-0001-9491-1822 function. ${ }^{5-7)}$ Determining the pathophysiological basis of $\mathrm{AHs}$ is important for understanding the neurobiological processes underlying schizophrenia and for the development of more effective treatment strategies for patients who are unresponsive to existing therapies. Despite extensive research, little is known about the neurobiology underlying this phenomenon.

Over recent decades, neuroimaging research has attempted to determine the neural mechanism(s) involved in the development of $\mathrm{AHs}$ in patients with schizophrenia. Volumetric studies have consistently reported that severity of $\mathrm{AHs}$ is associated with reduced relative volume in the left auditory cortex, left amygdala, left insula, and prefrontal cortex. ${ }^{8-10)}$ In parallel, functional neuroimaging studies have uncovered various areas associated with AHs. In a meta-analysis, it was reported that hallucinators

(c) This is an Open-Access article distributed under the terms of the Creative Commons Attribution Non-Commercial License (http://creativecommons.org/licenses/by-nc/4.0) which permits unrestricted non-commercial use, distribution, and reproduction in any medium, provided the original work is properly cited. 
showed increased activation likelihoods in a distributed bilateral frontotemporal network that included Broca's area, the anterior insula, the precentral gyrus, the frontal operculum, middle and superior temporal gyri, the inferior parietal lobule, the hippocampus, and the parahippocampal region. ${ }^{11)}$ Results from the meta-analysis supported two hypotheses: (1) aberrant activation within frontal-temporal language areas during $\mathrm{AH}$ and (2) dysfunction in the verbal memory system that could lead to the occurrence of $\mathrm{AH}$.

To capture the neurobiological underpinnings of $\mathrm{AHs}$ directly, it is important to recruit patients with prominent and persistent $\mathrm{AHs}$ and to distinguish on- and off-set of AHs within an imaging session. Several functional magnetic resonance imaging ( $\mathrm{fMRI}$ ) studies used a buttonpressing approach ${ }^{12-14)}$ and a random-sampling method ${ }^{15)}$ to capture brain processes directly involved in generating AHs. However, the scanner noise generated during fMRI procedures can activate the auditory cortex and mask neural activity due to AHs. Positron emission tomography (PET) imaging is a relatively quiet process despite its lower spatial and temporal resolution versus fMRI. Only two reported PET studies selected homogeneous patients with prominent and frequent $\mathrm{AHs}^{16,17)}$ and checked for the occurrence of $\mathrm{AHs}$ during the scanning process. ${ }^{16)}$ They reported higher metabolic rates in the left superior and middle temporal cortices, bilateral superior medial frontal cortex, and left caudate nucleus ${ }^{16)}$ and in the right middle frontal gyrus (Brodmann area 46) ${ }^{17)}$ in patients with $\mathrm{AHs}$ versus non-hallucinating patients. Problems with those studies included that the time duration of $\mathrm{AHs}$ during the scanning process was not provided.

Comparing the neural activities in schizophrenic patients with AHs with those in normal controls would produce findings related not only to the neural correlates of $\mathrm{AHs}$ but also to disease-related neural correlates. Therefore, we thought that comparison between patients with $\mathrm{AHs}$ and without $\mathrm{AHs}$ would uncover distinctive neural correlates of $\mathrm{AHs}$ by avoiding the confounding effects of disease-related symptomatology other than AHs. This study was undertaken to investigate regional differences in neural activity between patients with and without $\mathrm{AHs}$ and to explore relationships between glucose metabolism and severity of $\mathrm{AHs}$ using high-resolution fludeoxyglucose $\left({ }^{18} \mathrm{~F}\right)\left(\left[{ }^{18} \mathrm{~F}\right] \mathrm{FDG}\right)-\mathrm{PET}$.

\section{METHODS}

\section{Participants}

We recruited 10 patients with schizophrenia reporting persistent, prominent, and predominant $\mathrm{AHs}$ and 12 ageand gender-matched patients with schizophrenia reporting no $\mathrm{AHs}$ at least for the past 3 months or no experience of AHs ever. Patients were screened at Chonbuk National University Hospital in Jeonju, Korea. Diagnoses were established using the Structured Clinical Interview for DSM-IV Axis I Disorders (SCID). ${ }^{18)}$ The characteristics of AHs were defined as follows: persistent as sustained over the past 3 months, prominent as occurring $\geq 10$ times/day and 3 days/week, and predominant as Positive and Negative Syndrome Scale (PANSS) ${ }^{19)}$ P1 score $\leq 3$ (mild) and $\mathrm{P} 3$ score $\geq 4$ (moderate). Exclusion criteria were alcohol or drug abuse within the last 6 months, claustrophobia, history of head trauma, other neurological disorders, pregnancy, and significant medical problems.

This study was approved by the ethical committees of Chonbuk National University Hospital (approval number: 2012-07-014) and Gachon University Gil Medical Center (approval number: GIRBD0027-2012) where the PET and MRI scans were performed. All participants gave oral and written informed consent after the objectives and procedures of the study had been explained.

\section{Assessment}

Within 1 week before PET imaging, psychopathology was evaluated by experienced psychiatrists using the PANSS, Calgary Depression Scale for Schizophrenia (CDSS), ${ }^{20)}$ and Social and Occupational Functioning Assessment Scale. ${ }^{21)}$ The Prospective and Retrospective Memory Questionnaire (PRMQ) ${ }^{22)}$ was also used to measure the level of cognitive functioning. The scores of the prospective and retrospective subscales of the PRMQ were calculated by summing the scores of items $1,3,5,7$, $10,12,14$, and 16 , and the rest of the items, respectively. On the day of PET imaging, the Psychotic Symptom Rating Scale for Auditory Hallucinations (PSYRATS-AH) ${ }^{23)}$ was used before the $\left[{ }^{18} \mathrm{~F}\right]$ FDG injection. All participants were right-handed. The 11 items of the PSYRATS-AH assess different dimensions of $\mathrm{AHs}$ and can be clustered in three factors: a physical characteristics factor (frequency, duration, location, and loudness), an emotional characteristics factor (amount and degree of negative content 
and of distress), and a cognitive interpretation factor (disruption, belief about origin, and attribution of control).

\section{Acquisition and Reconstruction of PET and MRI Data}

All patients were scanned with a high-resolution research tomograph (HRRT)-PET (Siemens, Knoxville, TN, USA) and a 7-T MRI (Magnetom; Siemens, Erlangen, Germany). The HRRT-PET is an ultra-high-resolution brain-dedicated PET scanner that has a transaxial in-plane resolution of $2.5-\mathrm{mm}$ full width at half maximum (FWHM) ${ }^{24,25)}$ All patients fasted for at least 6 hours before $\left[{ }^{18} \mathrm{~F}\right] \mathrm{FDG}$ PET scanning. A bolus injection of $\left[{ }^{18} \mathrm{~F}\right] \mathrm{FDG}$ (injected dose, $192.5 \pm 12.6 \mathrm{MBq}$ ) was administered intravenously. During uptake of $\left[{ }^{18} \mathrm{~F}\right] \mathrm{FDG}$ into the brain, patients were seated on a bed for 30 minutes. During $\left[{ }^{18} \mathrm{~F}\right] \mathrm{FDG}$ uptake, all patients measured the duration of AHs themselves using a stopwatch. After $\left[{ }^{18} \mathrm{~F}\right] \mathrm{FDG}$ uptake, an emission scan was performed in static scan mode for 30 minutes. After the emission scan, a transmission scan was conducted for 6 minutes 10 seconds using a ${ }^{137} \mathrm{Cs}$ point source for attenuation correction. After $\left[{ }^{18} \mathrm{~F}\right]$ FDG PET scans, 7-T MRI was scanned using a three-dimensional T1-weighted magnetization-prepared rapid gradient echo (3D T1MPRAGE) sequence for structural brain imaging. 3D T1MPRAGE images were acquired with the following parameters: repetition time $(T R)=1,900 \mathrm{~ms}$, echo time $(T E)=3.73 \mathrm{~ms}$, inversion time $(\mathrm{TI})=1,100 \mathrm{~ms}$, flip angle $=10^{\circ}$, voxel size $=0.75 \times 0.75 \times$ $0.75 \mathrm{~mm}^{3}$, and number of slices $=256$.

PET images were reconstructed using the 3D-ordinary Poisson ordered-subset expectation maximization (OP-OSEM3D) algorithm that was accelerated using symmetry and single-instruction multiple-data-based projection and back-projection techniques. ${ }^{26)}$ The reconstructed PET images were post-processed with decay correction and had a matrix of $256 \times 256 \times 207$ and iso-voxel resolution of $1.22 \times 1.22 \times 1.22 \mathrm{~mm}^{3}$. For the calculation of the $\left[{ }^{18} \mathrm{~F}\right]$ FDG standardized uptake value ratio (SUVR), the $\left[{ }^{18} \mathrm{~F}\right] \mathrm{FDG}$ PET emission data were reconstructed as a single frame.

\section{Data Processing and Statistical Analysis}

None of the patients with $\mathrm{AHs}$ was excluded because they all experienced AHs during the 30 minutes of $\left[{ }^{18} \mathrm{~F}\right] \mathrm{FDG}$ uptake. Images were inspected visually for motion artifacts by an expert in PET image quality assurance.
Spatial preprocessing and statistical analyses of the PET images were performed in Statistical Parametric Mapping 8 (SPM8; Wellcome Trust Centre for Neuroimaging, UK; http://www.fil.ion.ucl.ac.uk/spm). For spatial preprocessing, each patient's PET image was coregistered to the same patient's MRI image. Then, all MRI images with coregistered PET images were spatially normalized into the Montreal Neurological Institute (MNI) template used in SPM8. Finally, spatially normalized PET images were smoothed with a Gaussian kernel of 6-mm FWHM. To calculate $\left[{ }^{18} \mathrm{~F}\right]$ FDG SUVR values, the intensity value of each voxel in the PET image was divided by the mean intensity of all intracerebral voxels. ${ }^{27)}$ The $\left[{ }^{18}\right.$ F]FDG SUVR values were obtained in 116 predefined regions of interest (ROIs) using the automated anatomical labeling (AAL) program. ${ }^{28)}$

Demographic and clinical data were compared between the groups using two-tailed $t$ test or chi-square test. To compare regional glucose metabolism between the groups, we performed ROI-based analyses and voxel-based analyses. For the ROI-based analyses, 90 ROIs, excluding the cerebellum and vermis, were selected based on a literature review. ${ }^{29)}$ A two-tailed $p$ value $<0.05$ was considered to indicate a statistically significant value. In the voxel-based analysis, the level of statistical significance was set as $p<0.005$, uncorrected, with a minimum cluster size of 20 adjacent voxels. Between- group comparisons on regional $\left[{ }^{18} \mathrm{~F}\right] \mathrm{FDG}$ SUVR values were performed using a two-tailed $t$ test or analysis of covariance (ANCOVA), as appropriate. The correlations between the $\left[{ }^{18} \mathrm{~F}\right]$ FDG SUVR values and the severity of AHs assessed using PSYRATS-AH in patients with $\mathrm{AHs}$ were not analyzed because of small sample size. In ROI-based analysis, a two-tailed probability value of $p$ $<0.05$ was chosen as a statistically significant value. In voxel-based analysis, the level of statistical significance was defined as $p<0.005$ uncorrected with a minimum cluster size of 20 adjacent voxels. To correct for multiple comparisons, results were further analyzed using thresholds of family wise error (FWE) and false discovery rate (FDR) at $p<0.05$.

\section{RESULTS}

Demographic and clinical data of patients with $\mathrm{AHs}$ (AH group) and without $\mathrm{AHs}$ (non- $\mathrm{AH}$ group) are sum- 
Table 1. Demographic and clinical characteristics of the participants

\begin{tabular}{|c|c|c|c|}
\hline \multirow{2}{*}{ Variable } & \multicolumn{2}{|c|}{ Schizophrenia } & \multirow{2}{*}{$p$ value } \\
\hline & With AHs $(n=10)$ & Without AHs $(n=12)$ & \\
\hline Age $(y r)$ & $39.20 \pm 10.55$ & $31.00 \pm 9.09$ & $<0.064$ \\
\hline Education (yr) & $14.00 \pm 1.89$ & $13.83 \pm 1.99$ & $<0.843$ \\
\hline Married state, single/married/divorced & $8 / 1 / 1$ & $8 / 2 / 2$ & $<1.000$ \\
\hline Sex, male/female & $7 / 3$ & $8 / 4$ & $<1.000$ \\
\hline Age of onset (yr) & $26.80 \pm 9.44$ & $20.08 \pm 7.81$ & $<0.082$ \\
\hline CDSS & $8.00 \pm 5.44$ & $3.50 \pm 4.08$ & $<0.038^{*}$ \\
\hline Chlorpromazine equivalence (mg/day) & $856.00 \pm 654.17$ & $340.42 \pm 285.49$ & $<0.023^{*}$ \\
\hline Duration of illness (mo) & $136.20 \pm 76.07$ & $112.50 \pm 78.01$ & $<0.481$ \\
\hline PANSS total & $51.10 \pm 9.86$ & $40.92 \pm 9.09$ & $<0.020^{*}$ \\
\hline \multicolumn{4}{|l|}{ PRMQ } \\
\hline Prospective & $17.30 \pm 4.90$ & $14.83 \pm 6.39$ & $<0.330$ \\
\hline Retrospective & $18.30 \pm 6.3$ & $13.00 \pm 4.86$ & $<0.039^{*}$ \\
\hline \multicolumn{4}{|l|}{ PSYRATS-AH } \\
\hline Total & $24.50 \pm 6.47$ & $2.08 \pm 7.22$ & $<0.001^{*}$ \\
\hline Physical characteristics & $9.10 \pm 1.45$ & $0.67 \pm 2.31$ & $<0.001 *$ \\
\hline Emotional characteristics & $8.80 \pm 4.76$ & $0.92 \pm 3.18$ & $<0.001^{*}$ \\
\hline Cognitive interpretation & $6.60 \pm 1.90$ & $0.50 \pm 1.73$ & $<0.001 *$ \\
\hline SOFAS & $59.00 \pm 10.75$ & $66.67 \pm 11.93$ & $<0.132$ \\
\hline
\end{tabular}

Values are presented as mean \pm standard deviation or number only.

AHs, auditory hallucinations; CDSS, Calgary Depression Scale for Schizophrenia; PANSS, Positive and Negative Syndrome Scale; PRMQ, Prospective and Retrospective Memory Questionnaire; PSYRATS-AH, Psychotic Symptom Rating Scales-Auditory Hallucinations; SOFAS, Social and Occupational Functioning Assessment Scale.

*Statistically significant.

marized in Table 1. Significant differences between the groups were observed in the CDSS, chlorpromazine equivalence, PANSS total and - positive subscale total, PSYRATS-AH, and PRMQ retrospective subscale. For the PANSS subscales, only the positive scale score was significantly different between the groups $(p=0.002)$. The durations (second) of $\mathrm{AHs}$ that occurred in the $\left[{ }^{18} \mathrm{~F}\right] \mathrm{FDG}$ uptake were $787.64 \pm 684.48$ (range, 48.55-1,742.21) and 0 for the $\mathrm{AH}$ and non- $\mathrm{AH}$ groups, respectively.

As for the results on group differences, the ROI analysis demonstrated significantly lower SUVR in the orbital parts of right middle and inferior frontal gyri and medial parts of the superior frontal gyrus and higher SUVR in the left and right putamen in patients with $\mathrm{AHs}$ versus patients without AHs (Table 2). However, when controlled for the confounding factors (the CDSS, PRMQ retrospective subscale, and chlorpromazine-equivalent doses), no finding remained significant. The voxel-based analysis revealed greater activation in the left middle and inferior temporal gyri, left putamen, left and right fusiform gyri, and left cerebellum ( $p<0.005$, uncorrected) and less activation in the left superior, middle, and inferior frontal gyri, right inferior frontal gyrus, left precentral gyrus, and left and right
Table 2. ROI analysis demonstrating regional differences in SUVR values between the groups

\begin{tabular}{|c|c|c|c|}
\hline \multirow[b]{2}{*}{ Brain region } & \multicolumn{2}{|c|}{ Schizophrenia } & \multirow[b]{2}{*}{$p$ value* } \\
\hline & $\begin{array}{l}\text { With AHs } \\
(n=10)\end{array}$ & $\begin{array}{l}\text { Without AHs } \\
\quad(n=12)\end{array}$ & \\
\hline $\begin{array}{l}\text { Orbital part of right inferior } \\
\text { frontal gyrus }\end{array}$ & $2.51 \pm 0.14$ & $2.70 \pm 0.25$ & 0.044 \\
\hline $\begin{array}{l}\text { Orbital part of right middle } \\
\text { frontal gyrus }\end{array}$ & $2.71 \pm 0.14$ & $2.92 \pm 0.29$ & 0.044 \\
\hline $\begin{array}{l}\text { Medial part of superior } \\
\text { frontal gyrus }\end{array}$ & $2.50 \pm 0.14$ & $2.70 \pm 0.28$ & 0.047 \\
\hline Left putamen & $3.38 \pm 0.23$ & $3.17 \pm 0.22$ & 0.048 \\
\hline Right putamen & $3.37 \pm 0.21$ & $3.15 \pm 0.25$ & 0.038 \\
\hline
\end{tabular}

Values are presented as mean \pm standard deviation.

$\mathrm{ROI}$, region of interest; SUVR, standardized uptake value ratio; $\mathrm{AHs}$, auditory hallucinations.

*Analyzed by $t$ test.

middle cingulate gyri ( $p<0.005$, uncorrected) in the $\mathrm{AH}$ group versus the non- $\mathrm{AH}$ group (Table 3, Fig. 1). When corrected for the confounding factors including age and multiple comparisons, these findings were no longer significant. 
Table 3. Group differences in standardized uptake value ratio*

\begin{tabular}{|c|c|c|c|c|c|c|c|c|c|c|}
\hline \multirow{2}{*}{ Cluster location } & \multicolumn{3}{|c|}{ Cluster-level statistics } & \multicolumn{5}{|c|}{ Voxel-level statistics } & \multirow{2}{*}{$\begin{array}{c}\begin{array}{c}\text { Peak coordinates } \\
(\mathrm{MNI})\end{array} \\
\mathrm{x}, \mathrm{y}, \mathrm{z}(\mathrm{mm})\end{array}$} & \multirow{2}{*}{ Peak location } \\
\hline & $p \mathrm{FWE}$ & k & $p$, unc. & $p$ FWE & $p$ FDR & $t$ & $\mathrm{z}$ & $p$, unc. & & \\
\hline \multicolumn{11}{|l|}{$\mathrm{AHs}>$ non-AHs } \\
\hline $\begin{array}{l}\text { Left cerebellum } \\
\text { anterior lobe }\end{array}$ & 1.000 & 20 & 0.283 & 0.974 & 0.736 & 4.90 & 3.93 & $<0.001$ & $-14,-52,-22$ & $\begin{array}{l}\text { Left cerebellum_4_5/left } \\
\text { cerebellum_6 }\end{array}$ \\
\hline \multirow[t]{2}{*}{ Left temporal lobe } & 0.992 & 38 & 0.145 & 0.993 & 0.736 & 4.72 & 3.82 & $<0.001$ & $-40,-44,-6$ & $\begin{array}{l}\text { Left middle temporal gyrus } \\
\text { (BA19) }\end{array}$ \\
\hline & & & & 1.000 & 0.736 & 4.02 & 3.40 & $<0.001$ & $-50,-48,-2$ & $\begin{array}{l}\text { Left middle temporal gyrus } \\
\text { (BA20) }\end{array}$ \\
\hline Right limbic lobe & 1.000 & 21 & 0.272 & 0.999 & 0.736 & 4.54 & 3.72 & $<0.001$ & $40,-18,-34$ & Right fusiform gyrus (BA21) \\
\hline \multirow[t]{2}{*}{$\begin{array}{l}\text { Left inferior } \\
\text { temporal gyrus }\end{array}$} & 0.983 & 43 & 0.122 & 0.999 & 0.736 & 4.52 & 3.71 & $<0.001$ & $-40,-2,-32$ & $\begin{array}{l}\text { Left middle temporal gyrus/left } \\
\text { inferior temporal gyrus }\end{array}$ \\
\hline & & & & 1.000 & 0.736 & 4.37 & 3.62 & $<0.001$ & $-34,-2,-40$ & Left fusiform gyrus (BA20) \\
\hline Left fusiform gyrus & 1.000 & 25 & 0.232 & 1.000 & 0.736 & 4.31 & 3.58 & $<0.001$ & $-40,-42,-24$ & $\begin{array}{l}\text { Left cerebellum 6/left fusiform } \\
\text { gyrus }\end{array}$ \\
\hline $\begin{array}{l}\text { Left sub-lobar/Left } \\
\text { lentiform nucleus }\end{array}$ & 0.972 & 47 & 0.108 & 1.000 & 0.736 & 4.13 & 3.47 & $<0.001$ & $-30,0,6$ & Left putamen \\
\hline \multicolumn{11}{|l|}{$\mathrm{AHs}<$ non-AHs } \\
\hline $\begin{array}{l}\text { Left middle frontal } \\
\text { gyrus }\end{array}$ & 1.000 & 22 & 0.261 & 0.946 & 0.998 & 5.04 & 4.00 & $<0.001$ & $-46,8,42$ & $\begin{array}{l}\text { Left middle frontal gyrus/left } \\
\text { precentral gyrus (BA6) }\end{array}$ \\
\hline $\begin{array}{l}\text { Left inferior frontal } \\
\text { gyrus }\end{array}$ & 1.000 & 20 & 0.283 & 0.996 & 0.998 & 4.66 & 3.79 & $<0.001$ & $-30,24,-24$ & $\begin{array}{l}\text { Orbital part of left inferior } \\
\text { frontal gyrus (BA47) }\end{array}$ \\
\hline $\begin{array}{l}\text { Left middle frontal } \\
\text { gyrus }\end{array}$ & 1.000 & 21 & 0.272 & 1.000 & 0.998 & 4.38 & 3.62 & $<0.001$ & $-32,56,-4$ & $\begin{array}{l}\text { Orbital part of left middle frontal } \\
\text { gyrus/orbital part of left } \\
\text { superior frontal gyrus/left } \\
\text { superior frontal gyrus (BA10) }\end{array}$ \\
\hline $\begin{array}{l}\text { Right inferior } \\
\text { frontal gyrus }\end{array}$ & 1.000 & 20 & 0.283 & 1.000 & 0.998 & 4.36 & 3.61 & $<0.001$ & $28,24,-28$ & $\begin{array}{l}\text { Orbital part of right inferior } \\
\text { frontal gyrus (BA47) }\end{array}$ \\
\hline $\begin{array}{l}\text { Right cingulate } \\
\text { gyrus }\end{array}$ & 0.993 & 37 & 0.150 & 1.000 & 0.998 & 4.32 & 3.59 & $<0.001$ & $2,-28,32$ & $\begin{array}{l}\text { Left middle cingulate gyrus/right } \\
\text { middle cingulate gyrus }\end{array}$ \\
\hline
\end{tabular}

MNI, the Montreal Neurological Institute template; AHs, auditory hallucinations; FWE, family wise error; FDR, false discovery rate; $k$, number of adjacent voxels per cluster; unc., uncorrected; BA, Brodmann area.

*Thresholded at $p \leq 0.001$, uncorrected, cluster size $\geq 20$ voxels.

\section{DISCUSSION}

To determine the neural basis of AHs, we compared SUVR between patients with and without $\mathrm{AHs}$ and investigated correlations between SUVR and severity of $\mathrm{AHs}$ using $\left[{ }^{18} \mathrm{~F}\right]$ FDG-PET. To enhance the homogeneity of the $\mathrm{AHs}$, characteristics for persistent, prominent, and predominant $\mathrm{AHs}$ were clearly predefined. In the $\mathrm{AH}$ group, we observed hyperactivity in the putamen and temporal gyrus, and hypoactivity in several parts of the frontal gyrus and cingulate gyrus compared with the non-AH group. These findings support a neurocognitive model in which both bottom-up and top-down processes interact to produce these erroneous percepts. ${ }^{29,30)}$

With regard to the results of frontal activity, implicated in the pathogenesis of $\mathrm{AHs}$, several studies have reported hyperactivity in the right medial prefrontal gyrus, ${ }^{31)}$ medial and superior frontal gyri, ${ }^{32)}$ middle and superior frontal gyri, ${ }^{16)}$ and the frontal operculum. ${ }^{11)}$ However, hypoactivity has also been reported in the left premotor cortex ${ }^{33)}$ and bilateral superior frontal gyrus. ${ }^{34)}$ In the present study, we observed hypoactivity in the superior, middle, and inferior frontal gyri in both ROI and voxel-based analyses (albeit at an uncorrected level). Hypoactivity has been demonstrated in trait studies ${ }^{33,34)}$ comparing patients experiencing $\mathrm{AHs}$ with patients without $\mathrm{AHs}$ or healthy controls during tasks with verbal material or auditory stimuli. That is, they investigated the neural bases of the susceptibility to hallucinate, independent of the subjects' experience during scanning. As our study did not use a task during $\left[{ }^{18} \mathrm{~F}\right] \mathrm{FDG}$ uptake and all subjects in the $\mathrm{AH}$ group experienced $\mathrm{AH}$ s during uptake, our results may re- 


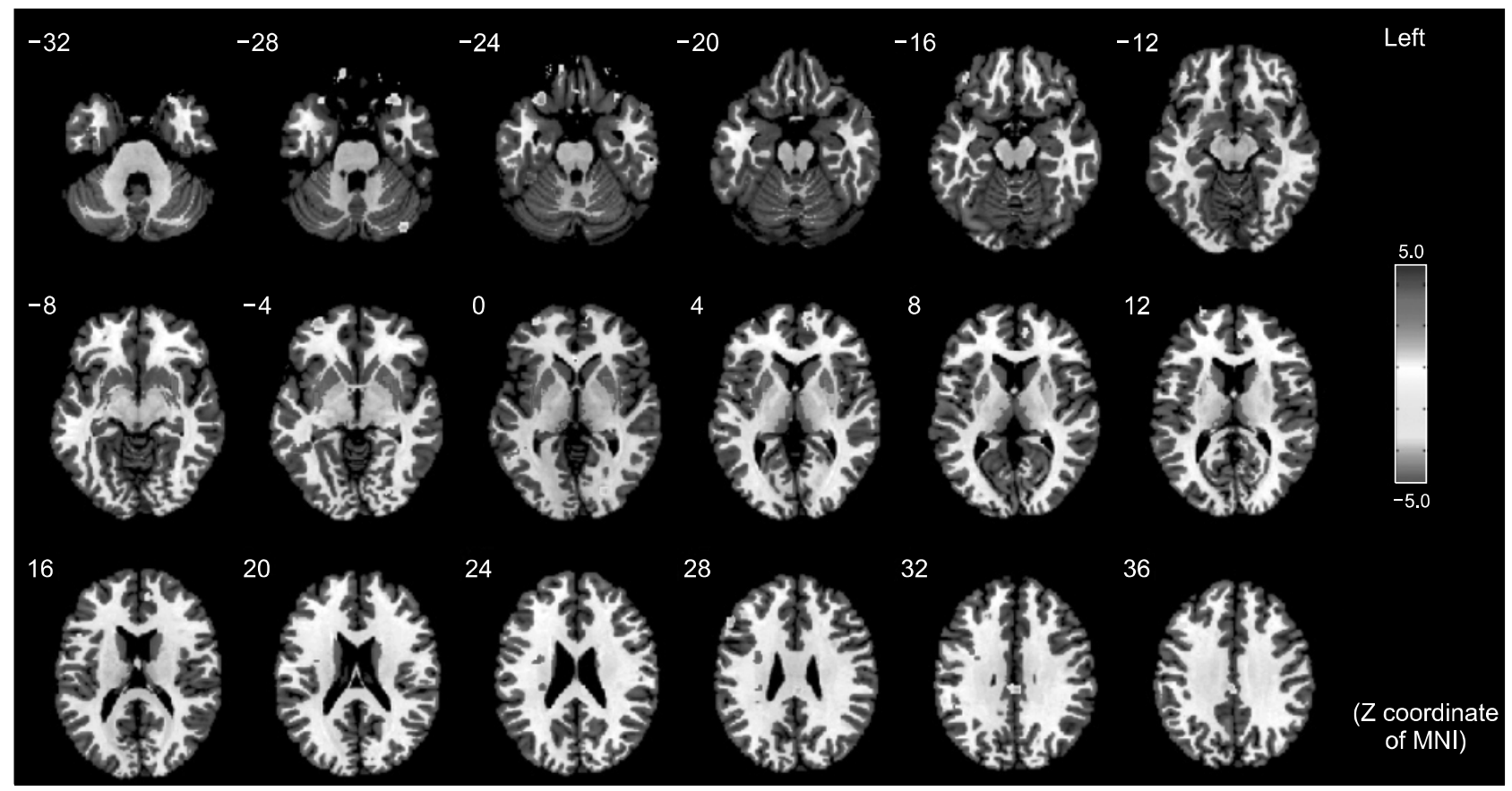

Fig. 1. Statistical parametric maps showing group differences: greater activation in the temporal gyrus and the putamen and lesser activation in the frontal and cingulate gyri in the auditory hallucinations (AHs) group compared to the non-AHs group (cluster size=20, $p<0.005$, uncorrected). $\mathrm{MNI}$, the Montreal Neurological Institute template.

flect direct measures of brain activation associated with AHs. In this regard, this is the first reported study demonstrating hypoactivity in the frontal areas as a neural mechanism of AHs. However, it should be noted that our findings may be associated with depression in patients with $\mathrm{AHs}$, not with $\mathrm{AHs}$ per se, because the score of the CDSS was significantly higher in patient with $\mathrm{AHs}$ compared to patients without $\mathrm{AHs}$ and positive findings were disappeared when controlling for depression. A recent meta-analysis on the changes of brain activity in depression reported that in resting condition, increased correlated activity was observed in the left amygdala, left parahippocampus, left claustrum, left putamen, right thalamus, and right posterior cerebellum and decreased activity was shown in the left superior temporal, right anterior cingulate, and left middle frontal regions under resting conditions. ${ }^{35)}$ In future study, it would be critical to recruit participants without depression or groups without difference in depression severity. Nontheless, implications of the findings may be as follows. The superior frontal gyrus is thought to contribute to higher cognitive functions, such as working memory, ${ }^{36)}$ task-switching, ${ }^{37)}$ and self-focused reappraisal. ${ }^{38)}$ The middle frontal gyrus is important in reorienting attention to an exogenous stimulus ${ }^{39)}$ and the right inferior frontal gyrus is important for inhibition ${ }^{40)}$ and hierarchical organization. ${ }^{41,42)}$ Assuming that both too much and too little are not good, abnormal activity in a certain brain area, regardless of direction, indicates impaired function in that area. Thus, our finding of hypoactivity in the frontal gyrus can be interpreted as indicating that, in the $\mathrm{AH}$ group, there may be impaired higher cognitive function, which may, in turn, cause a weakening of top-down control. This suggestion may be supported partially by the finding that the score of the PRMQ retrospective subscale in the $\mathrm{AH}$ group was significantly higher than in the non- $\mathrm{AH}$ group, indicating greater memory impairment. The anterior cingulate cortex plays a central role in the self-monitoring that is necessary for adaptive goal-directed behavior ${ }^{43)}$ and in exerting attentional control and selection for action. ${ }^{44)}$ We observed hypoactivity (decreased glucose metabolism) in the middle cingulate gyrus in the $\mathrm{AH}$ group, consistent with other studies. $^{33,45)}$ Hyperactivity in the cingulate cortex ${ }^{15,31,32,46)}$ has also been reported. Again, these abnormal activities in the cingulate gyrus/cortex may result in defective self-monitoring, causing impairment in top-down control.

The $\mathrm{AH}$ group showed increased activity in the putamen by ROI analysis. In voxel-based analysis, this was ex- 
panded to the middle and inferior temporal gyri, fusiform gyrus, and cerebellum. The result of increased activity in the putamen was rather unexpected in that it has classically been considered to be primarily a motor structure $^{47,48)}$. The activation may have been caused by hand movement in measuring the time duration of $\mathrm{AHs}$. Arguments against this interpretation are that we observed bilateral activation of the putamen (although only left putamen in the voxel-based analysis) and some studies reported increased activation in the left caudate nucleus ${ }^{16)}$ and left basal ganglia, ${ }^{49)}$ and decreased activity in the lenticular nucleus, ${ }^{50)}$ in which there was no hand movement to signal on- and off-set of AHs. An alternative explanation may be that given the role of the putamen in syntactic processing of sentence comprehension, ${ }^{51)}$ contents of $\mathrm{AHs}$ experienced in the $\mathrm{AH}$ group may contain syntactic errors. This needs to be investigated further in future studies. We observed significantly higher activation in the left middle and inferior temporal gyri in the $\mathrm{AH}$ group versus the non-AH group. Increased activity in the temporal lobe is the finding most frequently and consistently reported, especially in activity studies directly measuring brain activity occurring during the experience of hallucinations. ${ }^{29)}$ However, in trait studies that measured functional activity during auditory stimulation tasks, decreased activation of the temporal gyrus was observed. ${ }^{52)}$ This seemingly opposite phenomenon has been called a 'paradoxical effect', ${ }^{52)}$ suggesting a kind of 'competition for neuronal resources' between internally and externally generated neuronal activity. The middle temporal gyrus is known to be involved in several cognitive processes, including language and semantic memory processing ${ }^{53)}$ and perceiving inner speech. ${ }^{54,55)}$ The inferior temporal gyrus is associated with visual perception. ${ }^{56)}$ Thus, our results suggest that internally generated overrepresentations, stemming from abnormal processing in language/speech and visual stimuli, may be implicated in the pathogenesis of AHs. This concept differs from the previous theories explaining $\mathrm{AHs}$, such as overactivation of the auditory cortex, ${ }^{57)}$ and misattribution of internally generated speech, ${ }^{58,59)}$ which all involve the superior temporal gyrus. Taken together, our findings suggest that overrepresentations or errors in language/speech caused by hyperactivity in the middle temporal gyrus or putamen in addition to defective monitoring or top-down control related to the cingulate gyrus or frontal gyrus may contrib- ute to the pathophysiology of $\mathrm{AHs}$.

The current study has some limitations. First, there was no healthy control group, which may limit the interpretation of our findings. However, the comparison between patients with and without $\mathrm{AHs}$ has the advantage of distinguishing $\mathrm{AH}$-specific neural activities from disease-related effects. Second, given that most of the positive findings disappeared when controlling for confounding variables, it cannot be ruled out that our findings may be due to differences in depression, medication doses, and memory functioning. Third, we could not extend our positive findings with a threshold of $p$ FWE-corrected and $p$ FDR-corrected data. Despite these shortcomings, strengths of the present study are that we recruited homogeneous patients meeting the criteria for persistent, prominent, and predominant $\mathrm{AHs}$ and included only subjects experiencing $\mathrm{AHs}$ during $\left[{ }^{18} \mathrm{~F}\right] \mathrm{FDG}$ uptake period. Additionally, compared with conventional PET scanners, the HRRT-PET system used in our study has been reported to increase the accuracy of the quantification of glucose metabolism in brain regions due to decreased partial-volume effects. ${ }^{60)}$ In conclusion, our findings suggest that hypoactivity in the frontal and cingulate gyri, coupled with hyperactivity in the temporal gyrus and putamen, may contribute to the pathophysiology of $\mathrm{AHs}$.

\section{- Acknowledgments}

This study was supported by the Fund of the Biomedical Research Institute, Chonbuk National University Hospital. For Jong-Hoon Kim, this work was supported by the Brain Research Program through the National Research Foundation of Korea (NRF), funded by the Ministry of Science, ICT, and Future Planning (2016M3C7A1914451).

\section{REFERENCES}

1. van Os J, Linscott RJ, Myin-Germeys I, Delespaul P, Krabbendam L. A systematic review and meta-analysis of the psychosis continuum: evidence for a psychosis proneness-persistence-impairment model of psychotic disorder. Psychol Med 2009;39:179-195.

2. Larøi F, Sommer IE, Blom JD, Fernyhough C, Ffytche DH, Hugdahl K, et al. The characteristic features of auditory verbal hallucinations in clinical and nonclinical groups: state-of-theart overview and future directions. Schizophr Bull 2012; 38:724-733.

3. Carter DM, Mackinnon A, Copolov DL. Patients'strategies for coping with auditory hallucinations. J Nerv Ment Dis 1996; 
184:159-164.

4. Pantelis C, Barnes TR. Drug strategies and treatment-resistant schizophrenia. Aust N Z J Psychiatry 1996;30:20-37.

5. Breier A, Schreiber JL, Dyer J, Pickar D. National Institute of Mental Health longitudinal study of chronic schizophrenia. Prognosis and predictors of outcome. Arch Gen Psychiatry 1991;48:239-246.

6. Harkavy-Friedman JM, Kimhy D, Nelson EA, Venarde DF, Malaspina D, Mann JJ. Suicide attempts in schizophrenia: the role of command auditory hallucinations for suicide. J Clin Psychiatry 2003;64:871-874.

7. Lee SH, Choi BH, Song HS, Chung YC, Suh KY. Neurocognitive function and clinical characteristic in schizophrenia patients with treatment-resistant auditory hallucination. J Korean Neuropsychiatr Assoc 2004;43:288-295.

8. Barta PE, Pearlson GD, Powers RE, Richards SS, Tune LE. Auditory hallucinations and smaller superior temporal gyral volume in schizophrenia. Am J Psychiatry 1990;147:14571462.

9. Gaser C, Nenadic I, Volz HP, Büchel C, Sauer H. Neuroanatomy of "hearing voices": a frontotemporal brain structural abnormality associated with auditory hallucinations in schizophrenia. Cereb Cortex 2004;14:91-96.

10. Nenadic I, Smesny S, Schlösser RG, Sauer H, Gaser C. Auditory hallucinations and brain structure in schizophrenia: voxel-based morphometric study. Br I Psychiatry 2010;196: 412-413.

11. Jardri R, Pouchet A, Pins D, Thomas P. Cortical activations during auditory verbal hallucinations in schizophrenia: a coordinate-based meta-analysis. Am J Psychiatry 2011;168:73-81.

12. Dierks $T$, Linden DE, Jandl $M$, Formisano $E$, Goebel $R$, Lanfermann $\mathrm{H}$, et al. Activation of Heschl's gyrus during auditory hallucinations. Neuron 1999;22:615-621.

13. Silbersweig DA, Stern E, Frith C, Cahill C, Holmes A, Grootoonk $\mathrm{S}$, et al. A functional neuroanatomy of hallucinations in schizophrenia. Nature 1995;378:176-179.

14. Sommer IE, Diederen KM, Blom JD, Willems A, Kushan L, Slotema K, et al. Auditory verbal hallucinations predominantly activate the right inferior frontal area. Brain 2008; 131:3169-3177.

15. Shergill SS, Brammer MJ, Williams SC, Murray RM, McGuire PK. Mapping auditory hallucinations in schizophrenia using functional magnetic resonance imaging. Arch Gen Psychiatry 2000;57:1033-1038.

16. Horga G, Parellada E, Lomeña F, Fernández-Egea E, Mané A, Font $\mathrm{M}$, et al. Differential brain g/ucose metabolic patterns in antipsychotic-naïve first-episode schizophrenia with and without auditory verbal hallucinations. J Psychiatry Neurosci 2011;36:312-321.

17. Kopeček M, Spaniel F, Novák T, Tislerová B, Belohlávek O, Horácek J. 18FDG PET in hallucinating and non-hallucinating patients. Neuro Endocrinol Lett 2007;28:53-9.

18. First MB, Spitzer RL, Gibbon M, Williams JBW. Structured
Clinical Interview for DSM-IV-TR Axis I disorders, Research Version, Patient Edition (SCID-I/P). New York:Biometrics Research, New York State Psychiatric Institute;2002.

19. Kay SR, Fiszbein A, Opler LA. The Positive and Negative Syndrome Scale (PANSS) for schizophrenia. Schizophr Bull 1987;13:261-276.

20. Addington D, Addington J, Maticka-Tyndale E. Assessing depression in schizophrenia: the Calgary Depression Scale. BrJ Psychiatry Supp/ 1993;(22):39-44.

21. Goldman $\mathrm{HH}$, Skodol AE, Lave TR. Revising axis $V$ for DSM-IV: a review of measures of social functioning. Am J Psychiatry 1992; 149:1148-1156.

22. Crawford JR, Smith G, Maylor EA, Della Sala S, Logie RH. The Prospective and Retrospective Memory Questionnaire (PRMQ): Normative data and latent structure in a large nonclinical sample. Memory 2003;11:261-275.

23. Haddock G, McCarron J, Tarrier N, Faragher EB. Scales to measure dimensions of hallucinations and delusions: the psychotic symptom rating scales (PSYRATS). Psychol Med 1999; 29:879-889.

24. Cho ZH, Son YD, Kim HK, Kim KN, Oh SH, Han JY, et al. A fusion PET-MRI system with a high-resolution research tomograph-PET and ultra-high field 7.0 T-MRI for the molecular-genetic imaging of the brain. Proteomics 2008;8:13021323.

25. Wienhard K, Schmand M, Casey ME, Baker K, Bao J, Eriksson $\mathrm{L}$, et al. The ECAT HRRT: performance and first clinical application of the new high resolution research tomography. IEEE Trans Nucl Sci 2002;49:104-110.

26. Hong IK, Chung ST, Kim HK, Kim YB, Son YD, Cho ZH. Ultra fast symmetry and SIMD-based projection-backprojection (SSP) algorithm for 3-D PET image reconstruction. IEEE Trans Med Imaging 2007;26:789-803.

27. Molina V, Gispert JD, Reig S, Sanz J, Pascau J, Santos A, et al. Cerebral metabolic changes induced by clozapine in schizophrenia and related to clinical improvement. Psychopharmacology (Berl) 2005;178:17-26.

28. Tzourio-Mazoyer N, Landeau B, Papathanassiou D, Crivello F, Etard O, Delcroix N, et al. Automated anatomical labeling of activations in SPM using a macroscopic anatomical parcellation of the MNI MRI single-subject brain. Neuroimage 2002; 15:273-289.

29. Allen P, Larøi F, McGuire PK, Aleman A. The hallucinating brain: a review of structural and functional neuroimaging studies of hallucinations. Neurosci Biobehav Rev 2008;32: 175-191.

30. Hugdahl K. "Hearing voices": auditory hallucinations as failure of top-down control of bottom-up perceptual processes. Scand J Psychol 2009;50:553-560.

31. Copolov DL, Seal ML, Maruff P, Ulusoy R, Wong MT, Tochon-Danguy HJ, et al. Cortical activation associated with the experience of auditory hallucinations and perception of human speech in schizophrenia: a PET correlation study. 
Psychiatry Res 2003;122:139-152.

32. Parellada E, Lomena F, Font M, Pareto D, Gutierrez F, Simo M, et al. Fluordeoxyglucose-PET study in first-episode schizophrenic patients during the hallucinatory state, after remission and during linguistic-auditory activation. Nucl Med Commun 2008;29:894-900.

33. Kühn S, Gallinat J. Quantitative meta-analysis on state and trait aspects of auditory verbal hallucinations in schizophrenia. Schizophr Bull 2012;38:779-786.

34. Kang JI, Kim JJ, Seok JH, Chun JW, Lee SK, Park HJ. Abnormal brain response during the auditory emotional processing in schizophrenic patients with chronic auditory hallucinations. Schizophr Res 2009;107:83-91.

35. Palmer SM, Crewther SG, Carey LM; START Project Team. $A$ meta-analysis of changes in brain activity in clinical depression. Front Hum Neurosci 2015;8:1045.

36. du Boisgueheneuc F, Levy R, Volle E, Seassau M, Duffau H, Kinkingnehun S, et al. Functions of the left superior frontal gyrus in humans: a lesion study. Brain 2006;129(Pt 12):33153328.

37. Cutini S, Scatturin P, Menon E, Bisiacchi PS, Gamberini L, Zorzi $\mathrm{M}$, et al. Selective activation of the superior frontal gyrus in task-switching: an event-related fNIRS study. Neuroimage 2008;42:945-955.

38. Falquez R, Couto B, Ibanez A, Freitag MT, Berger M, Arens EA, et al. Detaching from the negative by reappraisal: the role of right superior frontal gyrus (BA9/32). Front Behav Neurosci 2014;8:165.

39. Japee S, Holiday K, Satyshur MD, Mukai I, Ungerleider LG. $A$ role of right middle frontal gyrus in reorienting of attention: a case study. Front Syst Neurosci 2015;9:23.

40. Hampshire A, Chamberlain SR, Monti MM, Duncan J, Owen AM. The role of the right inferior frontal gyrus: inhibition and attentional control. Neuroimage 2010;50:1313-1319.

41. Charron S, Koechlin E. Divided representation of concurrent goals in the human frontal lobes. Science 2010;328:360-363.

42. Koechlin E, Jubault T. Broca's area and the hierarchical organization of human behavior. Neuron 2006:50:963-974.

43. Paus T. Primate anterior cingulate cortex: where motor control, drive and cognition interface. Nat Rev Neurosci 2001;2: 417-424.

44. Posner MI, Dehaene S. Attentional networks. Trends Neurosci 1994; 17:75-79.

45. Allen P, Amaro E, Fu CH, Williams SC, Brammer MJ, Johns LC, et al. Neural correlates of the misattribution of speech in schizophrenia. Br J Psychiatry 2007;190:162-169.

46. McGuire PK, Shah GM, Murray RM. Increased blood flow in Broca's area during auditory hallucinations in schizophrenia. Lancet 1993;342:703-706.

47. Tolkunov BF, Orlov AA, Afanas'ev SV, Selezneva EV.
Involvement of striatum (putamen) neurons in motor and nonmotor behavior fragments in monkeys. Neurosci Behav Physiol 1998;28:224-230.

48. Ueda Y, Kimura M. Encoding of direction and combination of movements by primate putamen neurons. Eur I NeurosCi 2003;18:980-994.

49. Busatto GF, David AS, Costa DC, Ell PJ, Pilowsky LS, Lucey JV, et al. Schizophrenic auditory hallucinations are associated with increased regional cerebral blood flow during verbal memory activation in a study using single photon emission computed tomography. Psychiatry Res 1995;61:255-264.

50. Shergill SS, Bullmore E, Simmons A, Murray R, McGuire P. Functional anatomy of auditory verbal imagery in schizophrenic patients with auditory hallucinations. Am J Psychiatry 2000;157:1691-1693.

51. Friederici $\mathrm{AD}$, Rüschemeyer $\mathrm{SA}$, Hahne A, Fiebach $\mathrm{CJ}$. The role of left inferior frontal and superior temporal cortex in sentence comprehension: localizing syntactic and semantic processes. Cereb Cortex 2003;13:170-177.

52. Kompus K, Westerhausen R, Hugdahl K. The "paradoxical" engagement of the primary auditory cortex in patients with auditory verbal hallucinations: a meta-analysis of functional neuroimaging studies. Neuropsychologia 2011;49:33613369.

53. Chao LL, Haxby JV, Martin A. Attribute-based neural substrates in temporal cortex for perceiving and knowing about objects. Nat Neurosci 1999;2:913-919.

54. Démonet JF, Chollet F, Ramsay S, Cardebat D, Nespoulous JL, Wise $\mathrm{R}$, et al. The anatomy of phonological and semantic processing in normal subjects. Brain 1992;115:1753-1768.

55. McGuire PK, Silbersweig DA, Murray RM, David AS, Frackowiak RS, Frith CD. Functional anatomy of inner speech and auditory verbal imagery. Psycho Med 1996;26:29-38.

56. Herath P, Kinomura S, Roland PE. Visual recognition: evidence for two distinctive mechanisms from a PET study. Hum Brain Mapp 2001;12:110-119.

57. Penfield W. Some mechanisms of consciousness discovered during electrical stimulation of the brain. Proc Natl Acad SCi US A 1958:44:51-66.

58. Frith CD, Done JD. Towards a neuropsychology of schizophrenia. Br J Psychiatry 1988;153:437-443.

59. Mechelli A, Allen P, Amaro E Jr, Fu CH, Williams SC, Brammer MJ, et al. Misattribution of speech and impaired connectivity in patients with auditory verbal hallucinations. Hum Brain Mapp 2007;28:1213-1222.

60. Heiss WD, Habedank B, Klein JC, Herholz K, Wienhard K, Lenox $\mathrm{M}$, et al. Metabolic rates in small brain nuclei determined by high-resolution PET. J Nucl Med 2004;45:18111815. 